\title{
Avaliação da prevalência de células de Haller e sua relação com alterações maxilofaciais
}

\author{
- Cesar B. Albuquerque Departamento de Estomatologia, Faculdade de Odontologia, Universidade de São Paulo, São Paulo, \\ SP, Brasil • Nataly R. M. Zambrana Departamento de Estomatologia, Faculdade de Odontologia, Universidade de São Paulo, \\ São Paulo, SP, Brasil • Jéssica R. M. Zambrana Departamento de Estomatologia, Faculdade de Odontologia, Universidade \\ de São Paulo, São Paulo, SP, Brasil • Rodrigo A. Ribeiro Departamento de Estomatologia, Faculdade de Odontologia, \\ Universidade de São Paulo, São Paulo, SP, Brasil • Daniela M. R. A. Salgado Departamento de Estomatologia, Faculdade de \\ Odontologia, Universidade de São Paulo, São Paulo, SP, Brasil • Claudio Costa Departamento de Estomatologia, Faculdade \\ de Odontologia, Universidade de São Paulo, São Paulo, SP, Brasil
}

RESUMO | Introdução: As células de Haller são descritas como células etmoidais aeradas, localizadas na margem inferior da órbita, próximas aos óstios dos seios maxilares. A tomografia computadorizada de feixe cônico (TCFC) tem amplo uso na odontologia, permitindo aquisição de imagens da região craniofacial. Objetivo: Identificar, em exames de TCFC, a relação da célula de Haller com as seguintes condições: sinusopatia, desvio de septo nasal ósseo, tratamento endodôntico e lesões periapicais. Materiais e métodos: Foram utilizados 99 exames de TCFC, sendo 51 incluídos nos critérios da pesquisa. As imagens foram analisadas no software Xelis Dental ${ }^{\circledR}$, de maneira a identificar a presença ou não da célula de Haller, bem como sua relação com as condições citadas. Resultados: Dentre os 51 exames de TCFC avaliados, 35,3\% apresentaram célula de Haller do lado direito e 23,5\% no lado esquerdo. Levando-se em conta a relação das células de Haller com uma ou mais alterações aqui citadas, no lado direito a tivemos em $72 \%$ dos casos, enquanto no lado esquerdo tal relação se fez presente em $75 \%$ dos casos. Conclusão: Exames de TCFC que apresentam a margem infraorbital permitem verificar a presença ou ausência da célula de Haller. Nessa amostra, verificamos maior presença de casos de endodontia, desvio de septo e sinusopatia nos indivíduos que apresentaram células de Haller.

\section{DESCRITORES} Tomografia Computadorizada de Feixe Cônico; Radiologia; Seio Etmoidal.

ABSTRACT | Evaluation of prevalence of Haller cells and their relationship with maxilofacial changes - Introduction: The Haller Cells are described as aerated ethmoidal cells, located in the inferior margin of the orbit, near the ostia of the maxillary sinuses. The Cone Beam Computed Tomography (CBCT) is widely used in dentistry, allowing acquisition of images of the craniofacial region. Objective: to identify in CBCT exams the Haller's cell relationship with the following conditions: sinus disease, bony nasal septum deviation, endodontic treatment and periapical lesions. Materials and methods: 99 CBCT exams were used, from which 51 were included in the research criteria. The images were analyzed in the Xelis Dental ${ }^{\circledR}$ software to identify the presence or absence of the Haller Cell, as well as the relationship with the mentioned conditions. Results: Among the ${ }_{51}$ CFCT exams evaluated, $35.3 \%$ presented Haller's Cell on the right side and $23.5 \%$ on the left side. Whereas the relationship of the Haller Cells with one or more alterations mentioned here, on the right side we had it in $72 \%$ of the cases, while on the left side such relationship was present in $75 \%$ of the cases. Conclusion: CBCT exams that present the infraorbital margin allow to verify the presence or absence of the Haller Cell. In this sample, we verified a greater presence of endodontic cases, bony nasal septum deviation and sinus disease cases in individuals who presented Haller Cells. 


\section{INTRODUÇÃO}

A tomografia computadorizada (TC) utiliza uma fonte de raios $\mathrm{X}$ para a geração de imagens em três dimensões $(3 \mathrm{D})^{1} \mathrm{e}$, atualmente, é um dos métodos de diagnóstico mais importante, possibilitando aquisição de imagens em cortes sagitais, axiais e coronais, sem sobreposições entre tecidos e permitindo a observação da topografia total da área de interesse, não sendo passível de distorção, diferentemente da radiografia convencional. ${ }^{2}$

Na década de 1990, foi desenvolvida a tomografia computadorizada de feixe cônico $(\mathrm{TCFC})^{3}$, que diferentemente da TC, utiliza um feixe de raios $\mathrm{X}$ de formato cônico, direcionado para a região de interesse (ROI) do paciente, realizando uma única varredura de 360 graus, permitindo a identificação de anomalias maxilofaciais e das vias aéreas. ${ }^{4}$

O amplo uso da TCFC na odontologia se deve ao fato de que ela tem menor custo e dose de radiação comparada a TC, com adequada qualidade da imagem. Essa menor dose de radiação é que torna a TCFC mais segura para a obtenção de imagens craniofaciais, sendo muito utilizada na odontologia para planejamento de implantes, avaliação de terceiros molares, endodontia, avaliação da ATM e auxílio no diagnóstico de alterações maxilofaciais. ${ }^{5}$

Algumas variações anatômicas do complexo maxilofacial necessitam de exames de imagem para serem avaliadas. Uma dessas variações é a célula de Haller. São descritas como células etmoidais aeradas, localizadas na margem inferior da órbita, próximas aos óstios dos seios maxilares. Podem apresentar aspectos e tamanhos variados. ${ }^{6-9}$ $\mathrm{O}$ entendimento da fisiologia da drenagem mucociliar dos seios paranasais e o surgimento da TC levantaram hipóteses de as células de Haller estarem associadas a sinusopatias. ${ }^{10}$

Este estudo visa avaliar a presença de células de Haller em imagens de TCFC, relacionada com presença das seguintes condições: sinusopatia, desvio de septo nasal ósseo, tratamento endodôntico e lesões periapicais.

\section{MATERIAIS E MÉTODOS}

\section{Seleção dla amostra}

As imagens de TCFC foram adquiridas a partir de pacientes que necessitaram desse método de diagnóstico por razões odontológicas, como implantes, cirurgias de terceiros molares, endodontia, entre outros. As imagens foram obtidas por meio do banco de dados do LAPI-FOUSP (Laboratório para Análise e Processamento de Imagens da Faculdade de Odontologia da Universidade de São Paulo).

No total, foram observadas 99 imagens de TCFC, de pacientes do sexo feminino, de diferentes faixas etárias, que faziam parte de um banco de dados de um estudo anterior.

\section{Critéríos de înclusão e exclusão}

Tendo-se, para a realização deste estudo, a necessidade de completa visualização das células de Haller no exame de TCFC, fez-se imprescindível que o campo de visão (FOV) englobasse o assoalho da órbita - margem infraorbital, cavidade nasal com septo, assoalho, conchas e meatos nasais, além dos seios maxilares.

Em contrapartida, imagens tomográficas que não abrangessem as estruturas anatômicas descritas foram descartadas, já que impossibilitariam a correta visualização das células de Haller e das demais alterações maxilofaciais citadas.

Desse total, 48 casos foram descartados por não apresentarem os critérios de inclusão, sendo incluídas no estudo 51 imagens de TCFC, que permitiam a avaliação detalhada da margem infraorbital, metodologia que será descrita a seguir.

\section{Aquisição das îmagens}

As imagens foram obtidas por meio do tomógrafo computadorizado de feixe cônico iCAT Classic ${ }^{\circledR}$ 
(Imaging Sciences International Inc., Hatfield, PA, EUA), com um protocolo de aquisição: regime de trabalho: $120 \mathrm{kVp}$ e $24 \mathrm{~mA}$; tempo de aquisição 20 segundos; tamanho do FOV $16 \mathrm{~cm} \mathrm{x} 22 \mathrm{~cm}$; 360 graus de rotação; sensor flat painel de Silício amorfo; profundidade de cinza de 14 bits e tamanho do voxel de $0,3 \mathrm{~mm}$.

\section{Avaliação das îmagens}

As imagens foram selecionadas no software XoranCAT $^{\circledR}$ (Xoran Techonologies, EUA), sendo armazenadas no formato DICOM (Digital Imaging and Communication in Medicine), para serem avaliadas no software Xelis Dental ${ }^{\circledR}$ (Infinitt, Coreia do Sul) sob Window $=4340$ e Level $=848$.

Foram avaliadas a presença e a ausência para os lados direito e esquerdo das células de Haller e das seguintes alterações: sinusopatia, desvio de septo nasal, tratamento endodôntico e lesão periapical.

Vale ressaltar que, neste trabalho, o termo "sinusopatia" refere-se ao velamento do seio maxilar, ao espessamento da mucosa sinusal e a cistos de revestimento. Estes serão aqui tratados de modo genérico - e não individualmente - em virtude de a formação acadêmica dos autores deste estudo não ser otorrinolaringológica.

A avaliação se dava nos três planos (sagital, coronal e axial) e foi realizada por um observador treinado.

Os dados obtidos foram tabulados, calculando-se a quantidade e a distribuição em porcentagem de cada uma das alterações.

\section{RESULTADOS}

Dentre os 51 exames de TCFC avaliados, a média

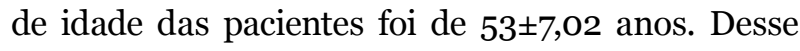
total, 18 exames apresentaram célula de Haller do lado direito - representando 35,3\% do total analisado -, e 12 exames apresentaram células de Haller no lado esquerdo - representando 23,5\% desse mesmo total.
Quanto à sinusopatia, no lado direito houve essa indicação em 17 exames (33,3\% do total) e, no lado esquerdo, em 20 (39,2\% do total). Já o desvio de septo nasal foi encontrado em 22 exames (43,1\% do total).

Quanto à variável tratamento endodôntico, no lado direito ela foi apontada em 22 exames (43,1\% do total); e no lado esquerdo, em 28 (54,9\% do total). Por último, a lesão periapical no lado direito apareceu em 12 exames (23,5\% do total) e, no lado esquerdo, em 15 (29,4\% do total) (Tabela 1 ).

Tabela 1 | Contagem das variações encontradas durante a avaliação individual de cada exame de TCFC.

\begin{tabular}{c|c|c}
\hline Analisados & $\begin{array}{c}\text { Número } \\
\text { de casos }\end{array}$ & $\begin{array}{c}\text { Percentual da } \\
\text { amostra avaliada (\%) }\end{array}$ \\
\hline Célula de Haller direita & 18 & 100 \\
\hline Célula de Haller esquerda & 12 & 35,3 \\
\hline Sinusopatia direita & 17 & 23,5 \\
\hline Sinusopatia esquerda & 20 & 33,3 \\
\hline Desvio de septo nasal & 22 & 39,2 \\
\hline Lesão periapical direita & 12 & 43,1 \\
\hline Lesão periapical esquerda & 15 & 23,5 \\
\hline Endodontia direita & 22 & 29,4 \\
\hline Endodontia esquerda & 28 & 43,1 \\
\hline
\end{tabular}

Considerando-se a relação das células de Haller com uma ou mais alterações aqui citadas, tivemos 13 casos - de um total de 18 - no lado direito, representando 72\%. Já no lado esquerdo, dos 12 casos em que as células de Haller estiveram presentes, em 9 deles tivemos uma associação com uma ou mais alterações, representando $75 \%$ desse total (Tabela 2).

As células de Haller foram relacionadas com o aparecimento das condições anteriormente citadas, quando no mesmo lado, de maneira quantitativa. No lado direito, houve a associação da célula de Haller com uma das alterações em 28\% dos casos, com duas alterações em $22 \%$ dos casos, com três alterações em 11\%, com quatro em $11 \%$ e com nenhuma alteração em $28 \%$ dos 
casos (Gráfico 1). Já no lado esquerdo, houve a associação das células de Haller com uma das condições citadas em $17 \%$ do total; com duas em 8\% dos casos; com três em 33\% dos casos; com quatro em $17 \%$ do total e com nenhuma alteração em 25\% dos casos (Gráfico 2).

Como exemplo ilustrativo do que foi relatado neste trabalho, temos uma situação (Figura 1) na qual é possível encontrar, no mesmo indivíduo e no mesmo lado, a presença de célula de Haller (seta A); espessamento da mucosa do seio maxilar (sugestivo de sinusopatia - seta B) e tratamento endodôntico (seta C). Em outro caso (Figura 2), temos também no mesmo lado e no mesmo indivíduo a presença de célula de Haller (seta A) e espessamento da mucosa do seio maxilar (sugestivo de sinusopatia - seta B).

Tabela 2 | Associação das células de Haller com uma ou mais alterações no mesmo lado.

\begin{tabular}{c|c|c|c|c|c|c}
\hline & \multicolumn{6}{|c}{ Alterações de mesmo lado das células de Haller } \\
\hline & 0 & 1 & 2 & 3 & 4 \\
\hline Célula de Haller direita & 5 & 5 & 4 & 2 & 2 \\
\hline Célula de Haller esquerda & 3 & 2 & 1 & 4 & 2 \\
\hline
\end{tabular}

Gráfico 1 | Associação entre a presença da célula de Haller no lado direito com uma ou mais alterações anatômicas descritas

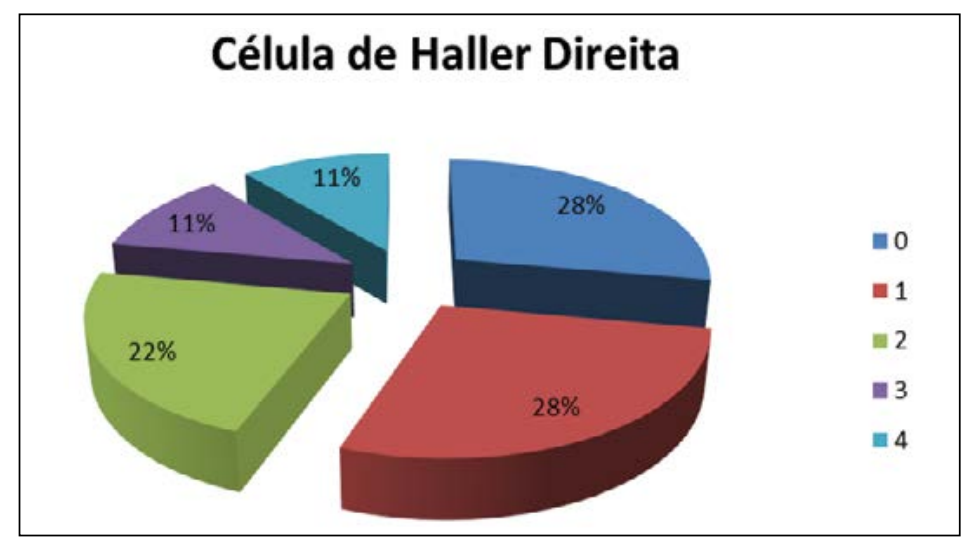

Gráfico 2 | Associação entre a presença da célula de Haller no lado esquerdo com uma ou mais alterações anatômicas descritas.

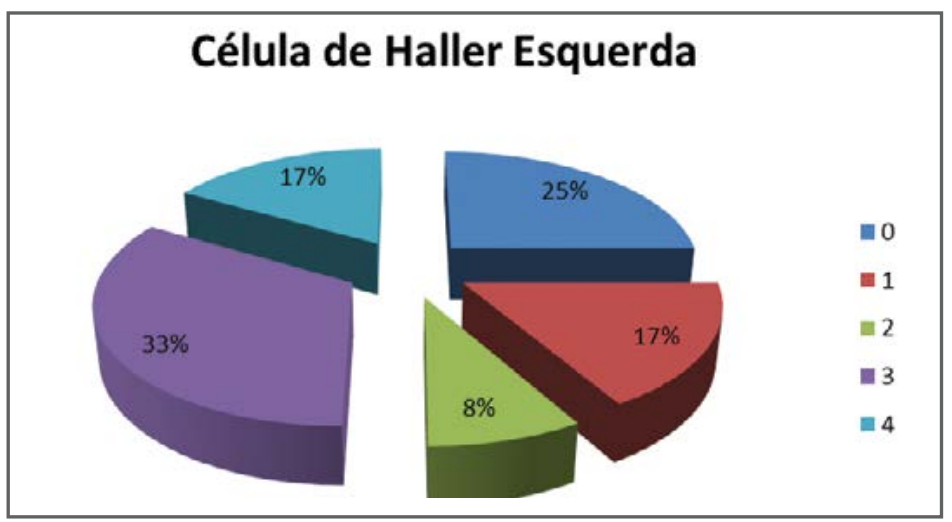



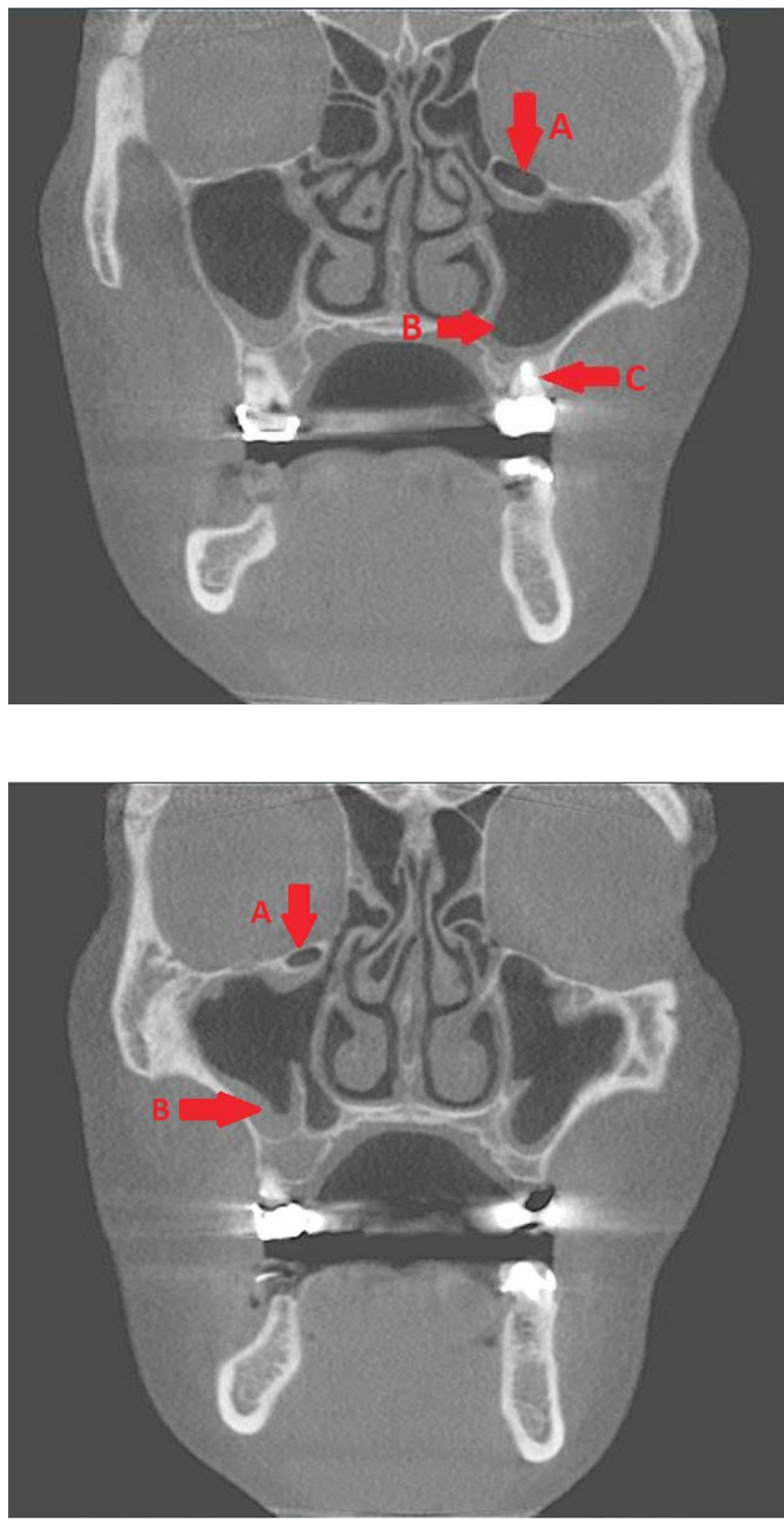

Figura 1 | De cima para baixo, as setas indicam, respectivamente: célula de Haller (A), espessamento da mucosa do seio maxilar (B) e tratamento endodôntico; todos no lado esquerdo (C).

Figura 2 As setas indicam, no lado direito do indivíduo, célula de Haller (A) e espessamento da mucosa do seio maxilar (B). 


\section{DISCUSSÃO}

As células de Haller são células etmoidais, localizadas inferiormente à bula etmoidal, ao longo do assoalho da órbita e relacionadas ao teto do seio maxilar. ${ }^{10,11} \mathrm{~A}$ prevalência dessas células é relatada na literatura como muito variável, estando entre $2,7 \%$ e $45,1 \%{ }^{12}$

Neste estudo observamos, conforme a Tabela 2, que no lado direito a associação da célula de Haller com alguma alteração aparece em 13 dos 18 casos, totalizando uma prevalência de $72 \%$. Em contrapartida, no lado esquerdo temos tal associação em 9 dos 12 casos existentes, totalizando $75 \%$ de prevalência. Com isso, tem-se uma diferença de $3 \%$ na prevalência da associação da célula de Haller com alguma das alterações citadas, não sendo esta uma diferença estatisticamente significante.

Podemos observar que o aparecimento das células de Haller está geralmente relacionado à sinusopatia, ao desvio de septo nasal ósseo, ao tratamento endodôntico e às lesões periapicais; aparecendo de maneira isolada na minoria dos casos.

Por se tratar de um assunto ainda controverso na literatura, não existe consenso se a presença de células de Haller está ou não associada a maior prevalência de sinusopatias.

De acordo com Kinsui et al. ${ }^{10}$, não há relação significante entre presença de célula de Haller e sinusopatia maxilar. O estudo aponta que a grande maioria dos autores não encontrou relação entre células de Haller e doença sinusal, sugerindo que os casos sejam avaliados individualmente. Em contrapartida, Earwaker ${ }^{11}$ sugeriu que as células de Haller poderiam ser um fator etiológico significativo no processo de sinusite maxilar recorrente, após ter encontrado uma prevalência de $\mathbf{2 0 \%}$.

É importante relatar que, durante toda a busca bibliográfica, não foi encontrado nenhum outro trabalho que relacionasse a presença de células de Haller com tratamento endodôntico e lesões periapicais, não sendo possível comparar os resultados desses itens obtidos neste estudo com qualquer outro. Entretanto, foi comprovado que devido à proximidade anatômica dos dentes posteriores com os seios maxilares, a presença de tratamento endodôntico e lesões periapicais podem estar associadas a sinusites odontogênicas. ${ }^{12}$

Ressaltamos que não é possível afirmar que a presença das células de Haller esteja realmente associada às alterações avaliadas anteriormente, por essas células serem consideradas variações anatômicas.

Em virtude de uma amostra pequena e com indivíduos do mesmo sexo, sugerimos que novos estudos sejam realizados, com um maior número de indivíduos, de diferentes faixas etárias e incluindo o sexo masculino, para que assim se possa enriquecer a base científica existente, fornecendo subsídio para conclusões mais concretas acerca do tema em questão.

\section{CONCLUSÃO}

Concluímos que, em exames de TCFC que apresentam a margem infraorbital, foi possível verificar a presença ou ausência da célula de Haller. $\mathrm{Na}$ amostra estudada, verificamos que houve maior presença de casos de endodontia, desvio de septo e sinusopatia nos indivíduos que apresentaram células de Haller.

\section{REFERÊNCIAS}

1. Frederiksen NL. Técnicas especiais de imagem. In: White SC, Pharoah MJ. Radiologia oral: fundamentos e interpretação. $5^{\mathrm{a}}$ ed. Rio de Janeiro: Elsevier; 2007. p. 247-64.

2. Valente NA, Soares BM, Santos EJC, Silva MBF. A importância da tomografia computadorizada de feixe cônico no diagnóstico e localização de dentes supranumerários. Rev Bras Odontol. 2016 mar;73(1):55-9.

3. Chilvarquer I, Hayek JE, Azevedo B. Tomografia: seus avanços e aplicações na odontologia. Rev Assoc Bras Radiol 2008 jul;9(1):3-9.

4. Enciso R, Shigeta Y, Nguyen M, Clark GT. Comparision of cone-beam computed tomography incidental findings 
between patients with moderate/severe obstructive sleep apnea and mild obstructive sleep apnea/healthy patients. Oral Surg Oral Med Oral Pathol Radiol. 2012 Sep;114:373-81. doi: 10.1016/j.oooo.2012.03.014.

5. Rodrigues MGS, Alarcón OMV, Carraro E, Rocha JF, Capelozza ALA. Tomografia computadorizada por feixe cônico: formação da imagem, indicações e critérios para prescrição. Odontol. Clín.-Cient. 2010 jun;9(2):115-8.

6. Kantarci M, Karensen RM, Alper F, Onbas O, Okur A, Karaman A. Remarkable anatomic variations in paranasal sinus region and their clinical importance. Eur J Radiol. 2004 Jun, 5O(3):296-302. doi: 10.1016/j.ejrad.2003.08.012.

7. Souza RP, Brito Júnior JP, Tormin OS, Paes Júnior JO, Barros CV, Trevisan FA, et al. Complexo nasossinusal: anatomia radiológica. Radiol Bras. 2006 Oct; 39(5):367-72. doi: dx.doi. org/10.159o/So100-39842006000500013.
8. Dwivedi AND, Singh KK. CT of the paranasal sinuses: normal anatomy, variants and pathology. J Optoelect Biomed Mat. 2010 Jan; 2(4):281-9.

9. Cashman EC, MacMahon, Smyth D. Computed tomography scans of paranasal sinuses before functional endoscopic sinus surgery. World J Radiol. 2011 Aug;3(8):199-204. doi: 10.4329/wjr.v3.i8.199.

10. Kinsui MM, Guilherme A, Yamashita HK. Variações anatômicas e sinusopatias: estudo por tomografia computadorizada. Rev Bras Otorrinolaringol. 2002 out; 68(5):645-52. doi: dx.doi. org/10.1590/Soo34-72992002000500008.

11. Earwaker J. Anatomic variants in sinonasal CT. Radiographics. 1993;13(2):381-415. doi: http://dx.doi. org/10.1148/radiographics.13.2.8460226.

12. Lima CO, Devito KL, Vasconcelos LRB, Prado M, Campos, CN. Sinusite odontogênica: uma revisão de literatura. Rev Bras Odontol. 2017 mar;74(1);40-4. doi: 10.18363/rbo.v74n1.p.40. 